\title{
1. Introduction: what is at stake?
}

\section{Julia Hörnle}

Matt attends Gamblers Anonymous meetings. He is addicted to online gambling and in particular online betting and casinos. In his bad, obsessive times he spent more than ten hours several times a week in front of the computer screen until the early hours of the morning, not caring about anything or anyone else. He realized for the first time something was wrong with him when he gambled away the money he and his girlfriend had saved for a holiday. Eventually he got into debt and hoping to recover the money, he placed higher and higher stakes, enjoying the adrenalin rushes caused by this. But when he lost, and he lost many times, he could not face up to his losses and suffered from depression and low self-esteem. He borrowed from friends and family, promising them to invest the money and entangled himself in a web of lies, ultimately costing him his job, the relationship with his girlfriend and child, his friends and his home. ${ }^{1}$

\subsection{AIMS AND SCOPE}

This book tells the story of an ongoing legal battle with uncertain outcomes. It is a battle between the extremely lucrative business of online gambling and states aiming to suppress this activity either for moral and social policy reasons or in order to protect their own (public) gambling provision, the revenue of which is used for social and cultural purposes. Fighting on the side of the gambling operators are the states aiming to attract gambling providers operating from their territory. ${ }^{2}$ These states are frequently island nations or other territories finding it hard to attract inward investment and hoping to create jobs and obtain a slice of the revenues in the form of taxation or licensing fees. The soldiers in this battle are the punters who, looking for a bit of fun and/or a quick buck, are more often than not losing their buck.

1 This is an entirely fictional story not based on any real story. For personal accounts of compulsive gambling and support groups see http://www.gamblersanonymous.org.uk last visited on 3 November 2009.

2 Many gambling providers targeting the US, Europe and beyond have (legally) established themselves in the Caribbean, for example in Antigua, or in Gibraltar, the Isle of Man, Alderney, Malta and the UK. 
This book tells the story of how this battle is fought through legislation prohibiting or allowing online gambling, through the courts imposing sanctions or ordering markets to be opened, and through enforcement authorities trying to figure out how to enforce the law against activities taking place partly on the territory of another state.

From a policy point of view, one encounters two diametrically opposed views on (online) gambling. From a liberal point of view, online gambling is a legitimate leisure pursuit, which people should be free to engage in. Holders of this point of view would concede that there are some risks associated with this activity, but that they are no different from the risks associated with many other leisure activities (such as drinking or dangerous sports).

From a moral (or religious) point of view gambling is a vice, which has little social utility and involves serious harm to health (addiction) and finances (overspending), which not only affects the gambler himself, but also his social environment (family, relationships, work). Holders of this second point of view may agree that gambling cannot be suppressed entirely, but contend that societies should aim to suppress it as far as possible and that gambling should not be a source of private profit, but revenues derived from it should go to 'good' causes.

A similar dichotomy exists between a neo-liberal economic point of view and the moral point of view. From a neo-liberal economic point of view, online gambling is an economic activity which creates income and employment and hence the role of the law is limited to facilitate economic transactions (and making them as safe as possible). From a moral point of view, law is grounded in moral principles, which on occasion have to override economic considerations.

These opposing points of views are not new as such and the debate is presumably as old as gambling itself. Therefore, in this book we will not cover in detail the moral, religious, philosophical or economic arguments for and against online gambling (interesting though they may be). Our focus is the law and the policy behind the law. Our approach is to examine and compare different forms of regulation and how these can (or cannot) be implemented across geographical borders.

What is fundamentally new about online gambling, however, is the fact that because of the ubiquity of the internet, it can be provided at a distance, remotely from one state, targeting the population of another state. The destination country, whose population engages in online gambling, will have the burden and cost to deal with gambling addiction and the harmful consequences of gambling without obtaining the revenue (in the form of taxation or income in the case of a state monopoly provider) derived from it. Interestingly, many countries attracting and allowing online gambling providers to operate from their territory prohibit the provision of online gambling services to their 
own population and thus provide for a preferential export regime, allowing service providers to circumvent or avoid regulation by the destination country. ${ }^{3}$ The destination country may try to regulate gambling carried out by its population, but may have difficulties in enforcing this regulation.

We will consequently look at the alternative approach adopted by some countries to regulate the service providers located within their country, such as financial intermediaries, advertisers and internet access providers and critically assess the effectiveness of such measures.

Some may call such indirect enforcement heavy-handed. At this early stage of the history of online gambling it is by no means clear whether or not the risks associated with gambling justify such a heavy-handed approach.

This book further addresses in detail the conflict of law issues of determining (1) which law applies to cross-border online gambling disputes, (2) which country's courts and enforcement agencies are competent to adjudicate such disputes and assume jurisdiction to regulate and (3) how such regulation may or may not be enforced. It also covers in detail the conflict between trade liberalization in the European Union (EU) and World Trade Organization (WTO) framework and states' assumption of jurisdiction to regulate and tax online gambling.

\subsection{OVERVIEW}

Online gambling is not a theoretical concept. It is already big business. According to the UK Gambling Commission, in 2008 remote gambling produced a turnover of $£ 896$ million from operators licensed in Great Britain alone. ${ }^{4}$ It was estimated that in 2005 punters spent US\$ 60 billion on online poker worldwide. ${ }^{5}$ Online gambling is estimated to have generated around US\$ 6 billion of revenue in the US in $2005 .^{6}$

Online gambling takes a variety of different forms. Traditional casino games such as roulette, table card games and slot machines are offered in a

3 See further, the discussion in A Littler 'Regulatory perspectives on the future of interactive gambling in the internal market' (2008) 33(2) European Law Review 211-29.

4 Gross gambling yield for remote betting, bingo and casino see UK Gambling Commission, Industry Statistics 2008/2009 p.15 http://www.gamblingcommission. gov.uk/pdf/Industry\%20statistics \%202008-2009\%20-\%20August\%202009.pdf.pdf last visited on 3 November 2009.

5 A Keen (2007) The Cult of the Amateur: How Today's Internet is Killing Our Culture (London: Nicholas Brealey) p. 148.

6 Ibid p. 152. 
virtual casino on many gambling websites. ${ }^{7}$ Online betting (pool betting and fixed odds betting) on horse-racing, other sports and events is convenient and popular. ${ }^{8}$ The internet has enabled a new form of betting: betting exchanges. ${ }^{9}$ Betting exchanges simultaneously match bets of several punters with opposite claims on the internet and charge a commission for doing so. ${ }^{10}$ They are able to offer higher odds, but have been criticized for allowing bets that a particular horse will lose, facilitating race-fixing. ${ }^{11}$

Some online betting websites also offer virtual horse- and dog-racing, where the underlying 'event' is a simulation game, with punters playing trainers, yard managers, owners, etc. and the outcome is determined by algorithms simulating the outcome of a real race. ${ }^{12}$

Another popular form of online gambling is online poker tournaments, where players are given an avatar and congregate in the shape of their avatar in a virtual space around a table, playing against each other, not the casino. ${ }^{13}$

A range of online number games are also offered, such as bingo ${ }^{14}$ or keno and online lottery draws. ${ }^{15}$

7 See for example http://www.partycasino.com/games/ (regulated in Gibraltar), http://casino.bodog.co.uk/ (regulated in Antigua), https://casino.bwin.com/casino.aspx (regulated in Gibraltar), http://casino.ladbrokes.com/en/table_games/type (regulated in Gibraltar), http://www.888.com/ (regulated in Gibraltar) last visited on 3 November 2009.

8 See for example http://www.sportingbet.com/Sports/Football/102 (Alderney), http://www.zeturf.com/en/ (Malta), http://www.ladbrokes.com/lbr_portal (Gibraltar), http://www.victorchandler.com/ (Gibraltar), http://sports.williamhill.com/bet/EN last visited on 3 November 2009.

9 http://www.betfair.com/ (regulated in the UK) last visited on 3 November 2009.

10 http://news.bbc.co.uk/1/hi/uk/7109494.stm\#anchor last visited on 3 November 2009.

11 http://news.bbc.co.uk/1/hi/uk/7106299.stm last visited on 3 November 2009.

12 http://www.zerace.com/accueil/default.aspx? 1 a =en \& pid=1; http://www.racing-index.com/virtual_horse_racing.html last visited on 3 November 2009.

13 http://www.fulltiltpoker.com/ (Alderney), http://www.pacificpoker.com/ pokerlisting2_en/ (Gibraltar), http://www.ladbrokes.com/en/affiliates/pokerlistings/ ?AFF_ID=20399\&ASSET_ID=3668 (Gibraltar), see also http://www.pokerlistings. com/poker-tournaments Screenshots of poker tables can be seen in the review for each poker tournament; last visited on 3 November 2009.

14 http://www.littlewoodsbingo.com/littlewoodsbingo/bingo/home/ (Gibraltar) last visited on 3 November 2009.

15 http://www.national-lottery.co.uk/player/p/home.ftl last visited on 3 November 2009. The UK National Lottery is by far the most popular form of online gambling in the UK, see Gambling Commission, 'Survey Data on Remote Gambling Participation', January 2009. 


\subsection{DEFINITIONS}

Since medieval times an attempt has been made in Europe to distinguish between prohibited and tolerated gambling. In this context definitions have made a distinction between three types of gambling (1) games of skill (where the outcome of the game is exclusively determined by skill) and (2) games of chance or luck (ludus azardus) and (3) mixed games (where the outcome is partly determined by skill and partly by chance). ${ }^{16}$

This distinction can still be found today in modern legal definitions of gambling, for example the British Gambling Act 2005. The law in Britain (and elsewhere) makes a basic distinction in the treatment of three different forms of gambling (as the overarching term): betting, gaming and lotteries. Betting is risking a stake of money on the outcome of an event (such as a race, competition or other, non-sports related event), the likelihood of something occurring or not occurring (such as will it snow in London on Christmas Day?) or whether something is true or not true. ${ }^{17}$ Gaming is usually defined as playing a game of chance (other than a sport) for a prize ${ }^{18}$, which means that the law normally excludes from the definition of gambling games where the outcome solely depends on skill. In Britain a game of chance, the outcome of which is partly determined by chance and partly determined by skill, amounts to gambling even if the element of chance can be eliminated by superlative skill, making the definition of gambling sufficiently wide to encompass card games such as poker, which require a significant element of skill. ${ }^{19}$ A distinction is also made between equal chance gaming (where the chance is equally favourable to all participants and there is no bank) and casino gaming. ${ }^{20} \mathrm{~A}$ lottery involves the payment of a sum of money for the chance of winning a prize, where the outcome is determined by a process relying wholly on chance. ${ }^{21}$ The process relies only wholly on chance if it prevents a significant proportion of persons from participating (because they do not have the requisite skills or knowledge). ${ }^{22}$ This provision has been included in the Gambling Act 2005 to distinguish prize competitions involving genuine skill, judgement and/or knowledge from lotteries designed to generate income. So, if a TV channel organizes a contest whereby viewers can phone a premium rate line to

\footnotetext{
16 M Zollinger, Geschichte des Glückspiels (1997) (Bohlau Wien) 21.

17 See section 9(1) Gambling Act 2005.

18 See section 6(1).

19 See section 6(2)(a)(ii).

20 See sections 7 and 8 .

21 See section 14(1).

22 Section $14(5)$.
} 
answer a simple question in return for the chance to win a prize, this is likely to be a lottery rather than a prize competition. ${ }^{23}$

\subsection{HISTORICAL BACKGROUND}

Gambling is not a new phenomenon. Historians have argued that playing games has been part of all cultures, anchored in many cultural expressions ranging from language to war. ${ }^{24}$

In Europe, in the eighteenth and nineteenth centuries the aristocracy dissipated enormous fortunes playing jeux de hasard ${ }^{25}$ in spa towns, at balls, in clubs, festivals, social evenings, gambling at lotteries and at the races. ${ }^{26}$ For many this high play became an addiction that led them to ruin: Georgiana, the Duchess of Devonshire is an example of this, see for example, the note in the Morning Post and Daily Advertiser of 4 September 1776:

Gaming among the females at Chatsworth has been carried to such a pitch that the phlegmatic Duke has been provoked to express at it and he has spoken to the Duchess in the severest terms against a conduct which has driven many from the house who could not afford to partake of amusements carried on at the expense of $£ 500$ or $£ 1000$ a night. $^{27}$

Georgiana had arranged the drawing room to resemble a professional gaming house, complete with hired croupiers and a commercial faro bank (...) Lady Mary Coke told her relations in Scotland that the Duchess of Devonshire was living a twentyfour-hour day of gambling and amusements. ${ }^{28}$

Faced with a constantly rising debt, Georgiana was haunted and harried by her creditors and tried to hide her gambling debts from her husband by

23 Phone-in contests (with or without prize) are popular on UK TV channels; however recently there have been media reports about serious irregularities and unfair practices which resulted in fines by the regulators OFCOM and PhonepayPlus, see for example http://www.guardian.co.uk/media/2008/may/08/itv; see also the Gambling Commission's Guidance on Prize Competitions and http://www.gamblingcommission.gov.uk/pdf/Prize $\% 20$ competitions $\% 20$ and $\% 20$ free $\% 20$ draws $\% 20-\% 20$ The $\%$ 20requirements \%20of\%20the\%20Gambling\%20Act $\% 202005 \% 20-\% 20$ November \%202007.pdf last visited on 3 November 2009.

24 M Zollinger.

25 Games of chance.

26 M Zollinger.

27 Quoted in Amanda Foreman's biography of Georgiana, the Duchess of Devonshire (1999) (London: Harper Collins) p. 44.

28 Ibid pp. 89-90. 
borrowing money from other sources. ${ }^{29}$ She confessed to a friend that she had incurred a 'very, very large debt. I never had courage to own it, and try'd to win it at play, by which means it became immense and was grown (I have not the courage to write the sum, but will tell you when I see you) many, many, many thousands. ${ }^{30}$ In $1786-7$ she had accumulated a gambling debt of roughly $£ 6000000$ (in today's equivalent). ${ }^{31}$

Much gambling occurred in fashionable spa resorts in the eighteenth and nineteenth centuries, named after the Belgian town of Spa, which was seen as the metropolis of gambling in the eighteenth century. ${ }^{32}$ Fyodor Dostoevsky notoriously gambled away large amounts of his money in various German spa town casinos (Wiesbaden, Baden-Baden and Bad Homburg) - an experience, the addictiveness of which he vividly describes in the novel The Gambler (1867).

Poorer sections of society also played games of chance with cards and dice, only some of which were legal, attended and betted at various events including cock-fighting, hare coursing ${ }^{33}$ and took part in official lotteries. ${ }^{34}$ There was an early contradiction between official lotteries and suppressing the playing of games of chance for poorer sections of society. ${ }^{35}$

It seems that the cat and mouse play between gamblers and enforcement authorities also is not new, as an article in the Neue Wiener Tagblatt of 1 March 1919 describes:

the addresses of the flats, in which gambling takes place every night, are passed from one person to another; there is a requirement to be introduced by at least two members and to know the constantly changing password to gain access to these salons, and the fact that the location of the gambling saloons changes from time to time, make the police investigations so much harder. ${ }^{36}$

With online gambling in the twenty-first century, however, enforcement obstacles have taken on a new dimension, as there is no physical space as such where the punters meet and the gambling takes place. Computer servers hosting the

\footnotetext{
29 Ibid pp. 126, 133-4, 189, 190-2, 230, 240-41, 253.

$30 \quad$ Ibid p. 134.

31 Ibid p. 183.

32 M Zollinger.
}

33 Hare coursing, a blood sport where two or more greyhounds chase a hare, was originally a sport engaged in only by nobility and became popular among the lower classes only in the nineteenth century; its popularity peaked in the nineteenth century and declined in the early twentieth century, as urban dog-racing courses were established, see http://en.wikipedia.org/wiki/Hare_coursing last visited on 3 November 2009.

M Zollinger.

Ibid.

36 Quoted in M Zollinger; freely translated by the author. 
gambling data and the gambling service providers may be located in a country (or several countries) other than the country wishing to enforce its laws. This de-localization of gambling cannot be better illustrated than by the example of gambling in virtual worlds.

\subsection{DE-LOCALIZED GAMBLING IN VIRTUAL WORLDS: VIRTUAL GAMES AND VIRTUAL MONEY}

Virtual worlds are simulations of reality in cyberspace, where users represented by their avatar, interact with each other. The software creating this virtual world allows more or less realistic 3D graphical representation of the avatars, objects and their environment. Avatars in virtual worlds can walk, run, fly, make gestures, handle objects, speak to and interact with each other in ways possible and impossible in the real world. One of the largest of such virtual worlds is Second Life, created and owned by Linden Lab with 19 million user accounts in 2009. ${ }^{37}$ Second Life has its own 'currency', the Linden dollar, which can be purchased from Linden Lab and used to buy virtual objects and services (including gambling) and which can also be redeemed into US dollars. According to Linden Lab nearly US\$ 50 million change hands every month (in 2008). ${ }^{38}$ While such virtual worlds are currently mainly used for gaming and seem a matter of fantasy to many internet users at present, they have an important potential of widespread application for education, e-learning and e-training, virtual meetings, online dispute resolution, art exhibitions, fashion shows, product placement, marketing and many other uses. Thus virtual worlds are an important addition to the media landscape.

Virtual worlds may, of course, also be used for online gambling. This can take many different forms, for example users from a variety of geographical locations, represented by their avatars sitting round a virtual poker table, or a simulation of the horse-racing industry.

According to press reports Linden Lab was visited by FBI agents ${ }^{39}$ who decided to ban gambling in July $2007 .{ }^{40}$ Online gambling is largely illegal in

37 http://www.guardian.co.uk/technology/2009/jul/29/virtual-worlds last visited on 3 November 2009.

38 Press Release at http://lindenlab.com/pressroom/releases/22_09_09 last visited on 3 November 2009.

$39 \mathrm{http}: / /$ secondlife.reuters.com/stories/2007/04/03/fbi-probes-second-lifegambling/ last visited on 3 November 2009.

$40 \mathrm{http}: / /$ secondlife.reuters.com/stories/2007/07/26/linden-lab-outlaws-secondlife-gambling/; https://support.secondlife.com/ics/support/default.asp?deptID=4417 last visited on 3 November 2009. 
the US, where Linden Lab is established. ${ }^{41}$ However, an operator of a virtual world established in another jurisdiction where gambling is not regulated may well decide not to ban gambling or even promote the use of the platform for such cross-border activities.

Enforcement thus takes place on two levels: at the level of the enforcement authorities of a particular state and at the platform level. However, even if a virtual world operator decides to ban gambling, the question arises whether the operator itself is effectively able to enforce the ban on online gambling engaged in by users of the virtual world.

Before the ban, it was estimated that there were hundreds of casinos and virtual poker tables in Second Life. ${ }^{42}$ This raises the question whether any are left or whether new ones have developed. The rules of Second Life now state that all forms of online gambling are prohibited and Linden Lab may confiscate any virtual land or other objects used for gambling and may exclude users infringing the rules. Furthermore, in order to prevent users finding virtual casinos, Linden Lab blocks any advertising of gambling opportunities and acts on notifications of gambling activities in its abuse reporting system. In other words, Linden Lab operates a notice and take-down system whereby users report illegal activity and Linden Lab removes any such content and exclude the users engaged in such illegal activity. However, if users do not report such activity, it is hard to see whether the operator can find out about gambling activities. Users may find the casinos on external internet blogs and by word of mouth. Hence it is at least questionable how effective a ban is as such. An operator such as Linden Lab would have to constantly search its servers hosting the virtual world to find the code enabling the online gambling (casino, betting, poker, slot machines, virtual sports and races, etc.). This is not impossible, but may be time-consuming and expensive to implement.

However, before we look at the question of enforcement, the next chapter will examine why gambling is regulated and how.

41 Based in San Francisco; the legal situation is not entirely clear, see further the discussion in Chapter 2, section 2.3.2.3.

42 See for example http://www.youtube.com/watch?v=i7jkro8zvDA; http://www.youtube.com/watch?v=Fa5UrZ7D8vE\&feature=related; http://koti.mbnet. fi/mons last visited on 3 November 2009. 